\title{
GEOMAGNETIC SECULAR VARIATION AND THE 1969-1970 SECULAR JERK AT THE AFRICAN OBSERVATORIES
}

\author{
Tigistu Haile \\ Department of Earth Sciences, Faculty of Science, Addis Ababa University, PO Box 1176 \\ Addis Ababa, Ethiopia. E-mail: hbeimnet@hotmail.com
}

\begin{abstract}
All-day annual mean values of the $\mathrm{D}, \mathrm{H}$ and $\mathrm{z}$ components of the geomagnetic field from ten observatories in the African continent are used to study long period secular variations, effects of external signals for the variation in the recorded field and for the signatures of geomagnetic jerks in the African region. Polynomials of second or third degree are found to be adequate to represent the secular variation in the field for most of the observatories. This shows that no strong local anomalies exist over much of the continent and the source of the secular variation is deep seated. Departures from these trends are observed over the Southern African region. The residuals in the geomagnetic field components are shown to exhibit parallelism with the periods corresponding to the double solar cycle only for some of the stations. A clear latitudinal distribution in the geomagnetic component that exhibits the 1969-70 secular jerk is shown. The jerk appears in the plots of the first differences in $\mathrm{H}$ for the southern most observatories of Hermanus, Hartebeesthoek, and Tsumeb, while the Z plots show the jerk for near equatorial and equatorial stations of Antananarivo, Luanda Belas, Bangui and Addis Ababa. There is some indication for this jerk in the first difference plots of $D$ for the northern stations of M'Bour and Tamanrasset. The plots of D rather strongly suggest the presence of a jerk around 1980 at most of the stations.
\end{abstract}

Key words/phrases: Magnetic observatories, polynomial fitting, residuals, secular variation, secular jerk

\section{INTRODUCTION}

The magnetic field of the Earth has been observed to exhibit changes of remarkably wide spectral range that could be generally divided into short and long period variations. The short period/higher frequency variations of the field are linked with electric currents flowing in the ionosphere and magnetosphere and thus having their origin external to the earth. The longer period variations, on the other hand, are thought to be due to internal processes within the earth like the dynamo action within the fluid metallic outer core. Both these variations have been the subject of much investigation for quite some time and for good reasons. The long period internal/secular variations have been given much attention because of their importance in the study of the processes in the deep interior of the earth that could allow one to infer motions in the convecting fluid core. The external variations can be used to investigate the electrical conductivity of the Earth's crust and mantle (Banks, 1969; Achache et al., 1980; Bloxham and Gubbins, 1985; Courtillot and Le Mouel, 1976; 1988).

Many studies have used the analyses of observatory recorded annual mean values of the geomagnetic elements over several decades to investigate the behaviour of the secular variation of the dipole field over a locality and examine external influences (Campbell, 1980; Alldredge, 1983; Gavoret et al., 1986; Gubbins and Tomlinson, 1986; Rangarajan et al., 1996, Alexandrescu et al., 1997). In such investigations, it has also been established that the long-term time variations in the geomagnetic components could be well modelled by low degree polynomials of various degrees fitted to data recorded over significant duration (Courtillot and Le Mouel, 1976; Ducruix et al., 1980). The residual signals obtained after the removal of the polynomial fits from the data, on the other hand, have been used to examine for external field phenomena like the solar flare, the 11-yr sunspot cycle and/or double solar cycle effects.

Although ground recorded magnetic data in the African Continent were scarce during earlier 
period of the 19th Century, a series of observatories have been continuously registering geomagnetic data since the second half of the last Century. The purpose of the study reported in this paper is to analyse these observatory records and examine some characteristics of the variations in the geomagnetic field. Data from ten observatories are used to study the trends in secular variation over the continent, the effects of external variations on the recorded data and also look for signatures of events like the 1969-1970 geomagnetic secular acceleration observed in many world wide observatory records.

\section{DATA AND ANALYSIS}

All day annual mean values of the geomagnetic field components $\mathrm{H}, \mathrm{D}$ and $\mathrm{Z}$ - defined as being the averages over all days of the year and all times of the day- have been used. The data are from ten geomagnetic observatories in the African continent that have several decades of data of observatory quality. The IAGA codes and the locations of these observatories are depicted in Figure 1. Table 1 gives the station descriptions: geographic and geomagnetic co-ordinates along with the length of available data.

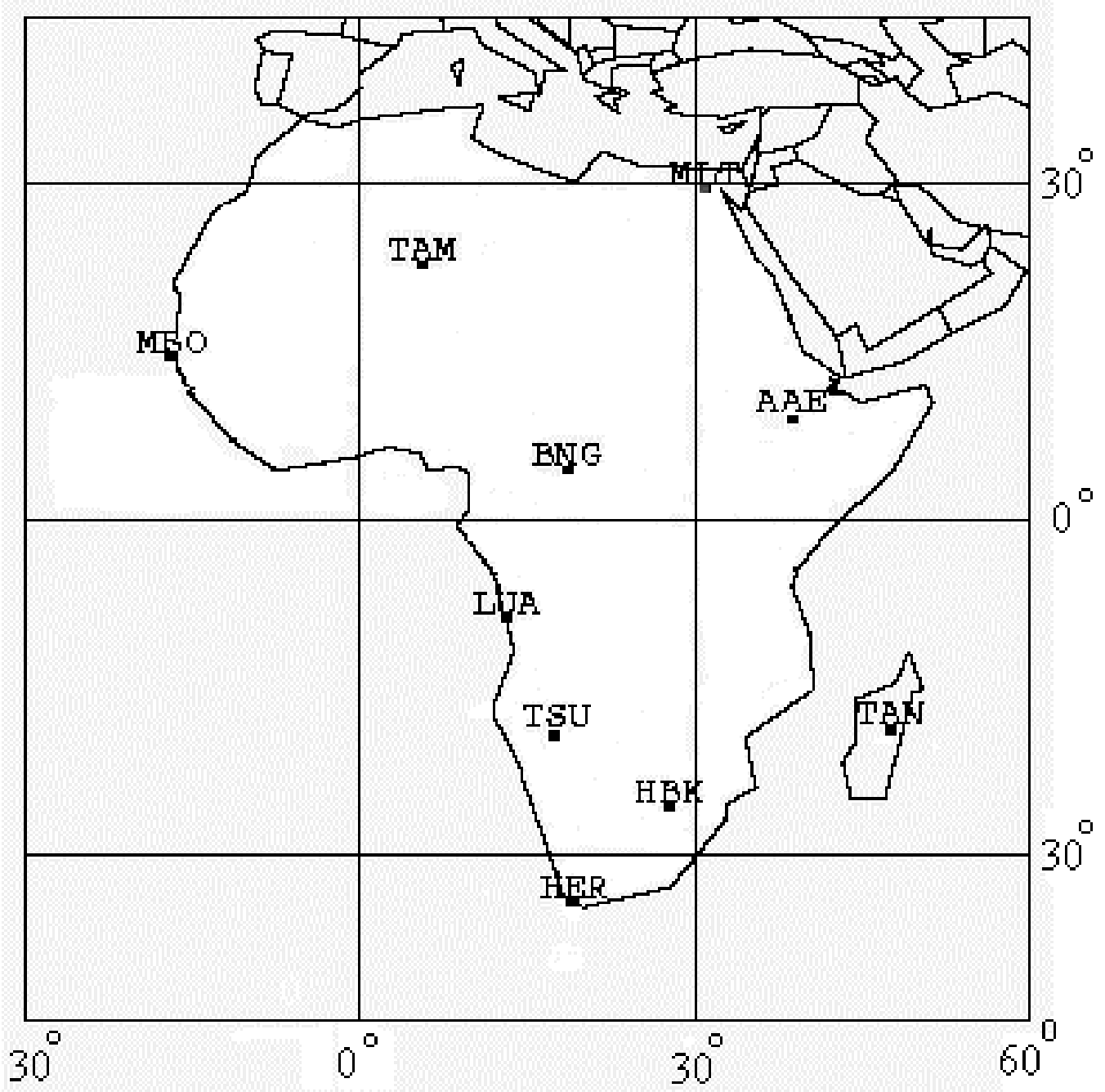

Fig. 1. The location of ten geomagnetic observatories in Africa with long time series data (see Table 1 for station descriptions). 
Table 1. Geomagnetic observatories in Africa with long time series data used in this work with station coordinates.

\begin{tabular}{|c|c|c|c|c|c|c|c|}
\hline \multirow{2}{*}{$\begin{array}{l}\text { IAGA } \\
\text { Code }\end{array}$} & \multirow{2}{*}{ Country (station) } & \multirow{2}{*}{$\begin{array}{l}\text { Elev. } \\
(\mathrm{m})\end{array}$} & \multicolumn{2}{|c|}{ Geographic co-ordinates } & \multicolumn{2}{|c|}{ Geomagnetic co-ordinates } & \multirow{2}{*}{ Length of Data } \\
\hline & & & Lat. $\left({ }^{\circ} \mathrm{N}, \mathrm{S}\right)$ & Long. $\left({ }^{\circ} \mathrm{E}\right)$ & Lat. $\left({ }^{\circ} \mathrm{N}, \mathrm{S}\right)$ & Long. $\left({ }^{\circ} \mathrm{E}\right)$ & \\
\hline$\overline{M L T}$ & Helwan/Misallat (Egypt) & 120 & 29.516 & 30.900 & 26.77 & 107.89 & $1903.5-1996.5$ \\
\hline TAM & Tamanrasset (Algeria) & 1373 & 22.79 & 5.533 & 24.73 & 81.64 & 1932.6-1999.5 \\
\hline Мво & M'Bour (Senegal) & 7 & 14.39 & 343.003 & 20.26 & 57.28 & 1952.6-1999.5 \\
\hline AAE & Ethiopia (Addis Ababa) & 2441 & 9.033 & 38.766 & 5.28 & 111.57 & 1958.5-1999.5 \\
\hline BNG & Bangui (C. African Rep.) & 395 & 4.433 & 18.567 & 4.33 & 90.94 & 1952.4-1999.5 \\
\hline LUA & Luanda Belas (Angola) & 53 & -8.916 & 13.166 & -7.81 & 83.20 & 1954.5-1993.5 \\
\hline TAN & Antananarivo (Madagascar) & 1375 & -18.916 & 47.552 & -23.73 & 115.49 & 1890.5-1999.5 \\
\hline TSU & Tsumeb (Namibia) & 83 & -19.20 & 17.583 & -18.72 & 85.56 & $1964.5-1997.5$ \\
\hline HBK & Hartebeesthoek (S. Afr.) & 1522 & -25.883 & 27.71 & -27.10 & 94.09 & 1973.5-1999.5 \\
\hline HER & Hermanus (S. Afr.) & 26 & -34.416 & 19.233 & -33.91 & 83.69 & 1941.5-1999.5 \\
\hline
\end{tabular}

It is seen from the table that the available data are of variable length. The observatory at Antananarivo gives data of more than ten decades, with a few data gaps in-between, while the Hartbeesthoek observatory gives very reliable but short length data of about three decades. For all stations, however, a nearly homogeneous data time series are available starting from the 1950's.

Furthermore, standard separate tabulations of quiet, disturbed and all day mean values have been made in these observatories only starting in the 1980's (except at Hermanus observatory where separate mean values are available from the beginning of observations at this location). Therefore, it becomes realistic to base the analysis on all day annual mean values and, accordingly, these are used in the analysis throughout. In any case, based on the analysis carried out on the Hermanus data and earlier results for other stations (e.g., Bhardwaj and Rangarajan, 1997 for the Indian region) the secular trend curves for all day annual means are found to be closely correlable to those of quiet day annual means. The annual means, of course, contain the daily, semiannual, annual variations and also of the sunspotcycle variation and its harmonics and their use do not restrict the validity of the analysis.

The paper relies heavily upon the graphic presentation of the analysis of the data and the visual inspection of the plots. The actual data, without corrections and adjustments, are plotted to observe the behaviour of the variation of the magnetic field components $\mathrm{D}, \mathrm{H}$ and $\mathrm{Z}$ with time at the individual stations and to look for any systematic variations in the secular trends, in the residual terms and the first differences of these components. The use of uncorrected data is believed to be also useful to examine the quality of data from each observatory and avoid unnecessary impositions on actual data.

Polynomials were fitted to the annual mean data using the method of propagation of least squares (Gangi and Shapiro, 1977). The technique employed to fit the data, moreover, permits the assessment as to which degree polynomial is essential to obtain the best fitting curves in contrast to the arbitrary termination of the fit to second (Courtillot and Le Mouel, 1976; 1984; 1988) or third (Rao and Bansal, 1969) degree. The trends, which are believed to correspond to the long period secular variation of internal origin, are then closely examined for their latitudinal and longitudinal correlation.

The secular/fitted trends are then subtracted from the original data to obtain the residuals, which in turn are expected to show variations of worldwide character imposed by factors of external origin like solar activities and other short period variations. The first difference of the field components, $\mathrm{dC} / \mathrm{dt}=\mathrm{C}(\mathrm{t}+1)-\mathrm{C}(\mathrm{t}-1)$, where $\mathrm{C}$ denotes the components $\mathrm{D}, \mathrm{H}$ and $\mathrm{Z}$ with ' $\mathrm{t}$ ' expressed in years, are then plotted to look for the signatures of geomagnetic secular variation impulses.

Analysis of data from the Antananarivo, the observatory with the longest time series data in the whole of the region, is given special emphasis and is presented separately for each case of trend 
analysis, residual analysis, and analysis in search of the signatures of geomagnetic impulses. The observed annual means of the three components $\mathrm{D}$, $\mathrm{H}$ and $\mathrm{Z}$ at Hermanus and Antananarivo stations in the southern most parts of Africa are also plotted separately and fitted to illustrate the fact that the southern African region is characterised by high local magnetic anomaly.

\section{RESULTS AND DISCUSSION}

The data analysis proceeds with the plots of all day annual mean data and the results are discussed in terms of (i) secular variation trends, (ii) behaviour of the observed periodic variations in the residuals and (iii) the search for signatures of geomagnetic impulses in the data. Results of the analysis for the component that exhibits larger variations and consistent trends are given and discussed.

\section{Secular changes in the geomagnetic field}

Plots of the $\mathrm{D}, \mathrm{H}$ and $\mathrm{Z}$ components of the geomagnetic field for Antananarivo observatory, the observatory with the longest time series data available in the region are given in Figure 2(a) along with their best fitting curves. The degree of fit or the percentage of fit taken care of by successive degrees of polynomials is given in Table 2 .
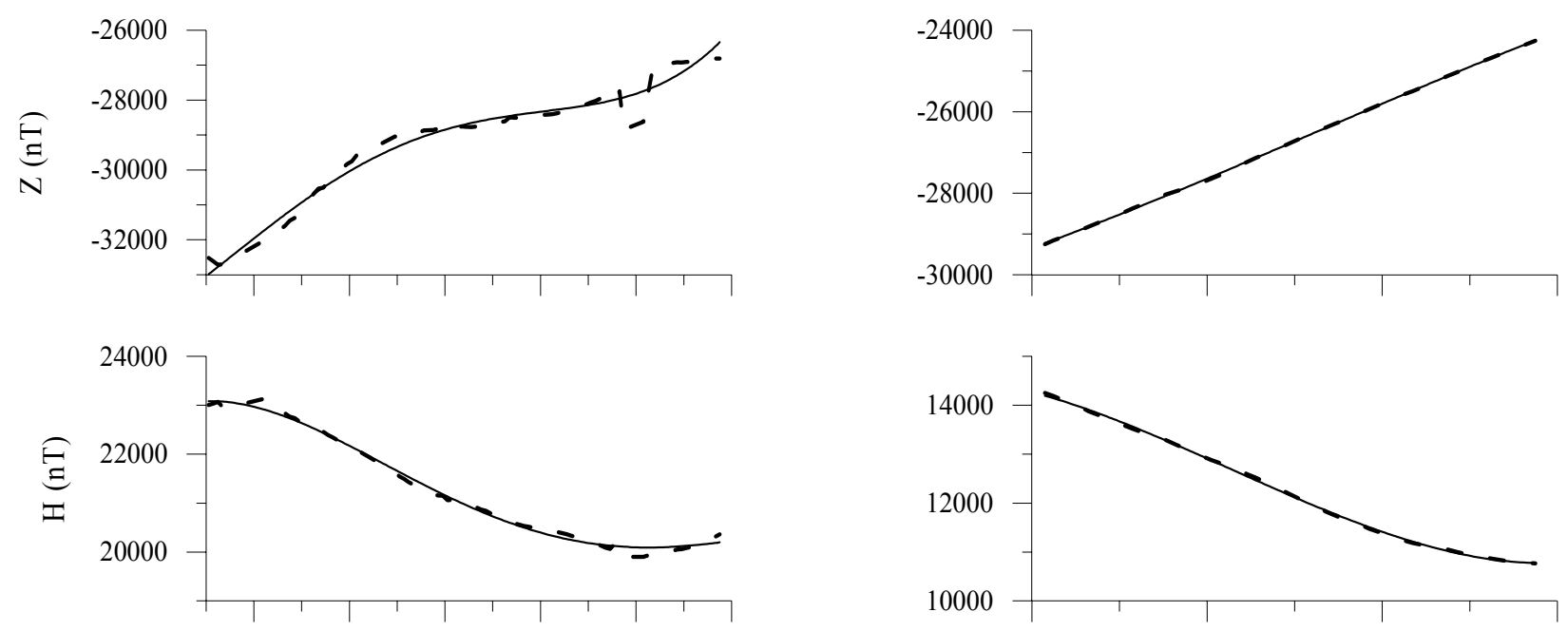

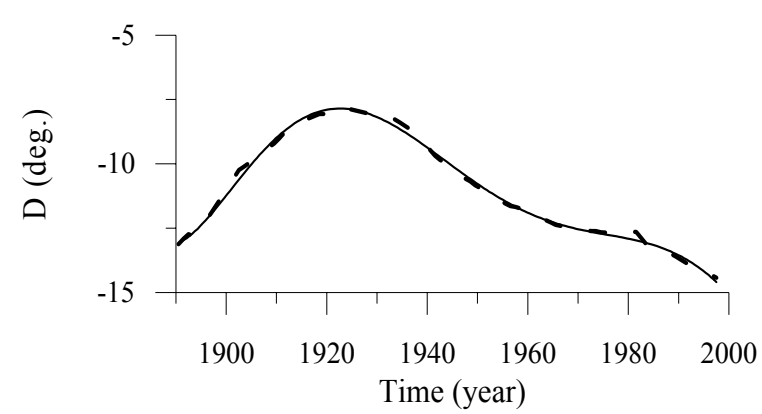

(a)

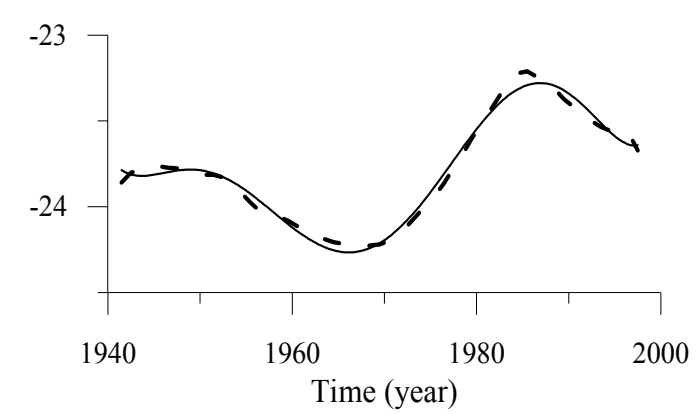

(b)

Fig. 2. Observed all day annual mean value of $D, H$ and $Z$ at (a) Antananarivo from 1890-1999 and (b) Hermanus from 19412000 along with their best fitting curves (solid line). Percentages of fit for successive polynomial degrees are given in Tables 2 and 3, respectively. 
Table 2. All day annual means accounted for by polynomial fits as given by the percentage of fit $\left(R^{2)}\right.$ for Antananarivo.

\begin{tabular}{cccccc}
\hline Comp. & $1^{\text {st }}$ Deg. & $2^{\text {nd }}$ Deg. & $3^{\text {rd }}$ Deg. & $4^{\text {th }}$ Deg. & $5^{\text {th }}$ Deg. \\
\hline D & 47.82 & 74.34 & 96.05 & 97.29 & 99.43 \\
H & 91.58 & 97.13 & 99.18 & 99.36 & 99.79 \\
$Z$ & 91.97 & 95.66 & 97.84 & 98.08 & 99.78 \\
\hline
\end{tabular}

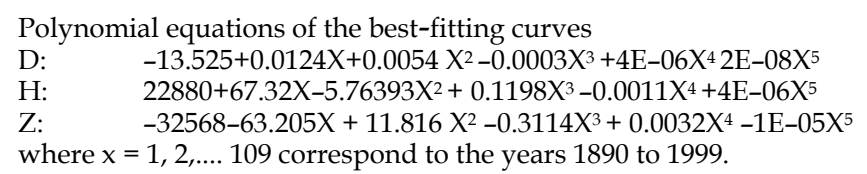

From Fig. 2(a) it is seen that both $\mathrm{H}$ and $\mathrm{D}$ had reached their maxima around 1900 and 1920 respectively and have since been decreasing at some non-linear rate while $\mathrm{z}$ has been increasing from what appears to be the minimum in the years around 1890. The rate of descent of $\mathrm{H}$ is nearly linear while in the case of $\mathrm{D}$ and $\mathrm{H}$ the change appears to be in phase after the 1930's.

Table 2 gives the aggregate percentage variance taken care of by each successive polynomial of higher degree. A degree-four to degree-five polynomial almost completely reproduces the observed variation of the geomagnetic field at this location of extended data length leaving little noise component in the data.

A rather more interesting comparison of the variation in the field and the degree of polynomials required to obtain adequate fits are provided by the data from the Hermanus observatory, a station which is closely located to Antananarivo (Figure $2 b)$ but with a more intense and irregular secular variation. With a shorter time series (as compared to Antananarivo) but with data of dependable quality, the variation in D at Hermanus shows a near sinusoidal periodicity of 40 years. Moreover, a third degree polynomial, adequate to almost completely reproduce the $\mathrm{H}$ and $\mathrm{Z}$ variations, leaves about $30 \%$ of the data of $\mathrm{D}$ unaccounted for (Table 3). The variations in $\mathrm{H}$ and $\mathrm{Z}$ at Hermanus, on the other hand, follow a similar trend to that of Antananarivo with a steady nearly linear decrease and increase, respectively, in the variations. Table 3 shows that the variations in these two components are almost completely reproduced by quadratic or cubic polynomials. The significant differences in the variations of $\mathrm{D}$ between these two, relatively closely spaced stations with latitudinal difference of slightly more than 10 degrees are the result of the South African region being a region of high local magnetic anomaly. The Hermanus and nearby observatories of Hartebeesthoek and Antananarivo are close to the centre of a large regional anomaly and close to the foci of secular variation (Courtillot and Le Mouel, 1976). This can also be ascertained both from global isodynamical maps plotted from DGRF models and from the departures observed during comparison of IGRF/DGRF model derived values with ground recorded observatory data (e.g., Baldwin and Langel, 1993; World Magnetic Model- Epoch 2000, http://www.ngdc.noaa.gov/seg/potfld/wMMIma ge.shtml).

\section{Secular variation at African observatories}

Figures $3(a, b, c)$ illustrate the geomagnetic data plotted for the ten African observatories for the period 1950-2000 along with their best-fitting secular trends. For all stations, all day annual mean values of the geomagnetic field starting from 1950 have been plotted because a reasonable comparison between the data can be made if one considers this time period.

The plots of values of declination $\mathrm{D}$ at the ten observatories, given in Figure 3(a), show a near linear increase in $\mathrm{D}$ at a rate of about 10' per year except the stations near the southern tip of Africa, a region of known strong local magnetic anomaly. In this region, the Tsumeb data show a slightly higher rate of increase in $\mathrm{D}$ as compared with the other stations while the observations at Antananarivo show a decrease in D. For Hermanus the plot shows a variation of near sinusoidal nature with periodicity of about 40 years. The data from Hartebeesthoek, which are of short duration, also show variations similar to that at Hermanus. 
Table 3. All day annual means accounted for by polynomial fits as given by the percentage of fit $\left(R^{2}\right)$ for Hermanus.

\begin{tabular}{ccccccc}
\hline Comp. & $1^{\text {st }}$ Deg. & $2^{\text {nd }}$ Deg. & $3^{\text {rd }}$ Deg. & $4^{\text {th }}$ Deg. & $5^{\text {th }}$ Deg. & $6^{\text {th }}$ Deg. \\
\hline $\mathrm{D}$ & 28.47 & 47.55 & 66.63 & 92.37 & 93.71 & 98.03 \\
Z & 98.52 & 99.49 & 99.94 & & & \\
\hline
\end{tabular}

Polynomial equations of the best-fitting curves

D: $\quad-23.753-0.0552 X+0.015 X^{2}-0.0015 X^{3}+6 E-05 X^{4}-1 E-06 X^{5}+6 E-09 X^{6}$

$\mathrm{H}: \quad 14249+49.522 \mathrm{X}-1.371 \mathrm{X}^{2}-0.021 \mathrm{X}^{3}$

Z: $\quad-29301+78.281 X+0.4431 X^{2}-0.0046 X^{3}$

where $X=1,2, \ldots .48$ correspond to the years 1941 to 1999 .

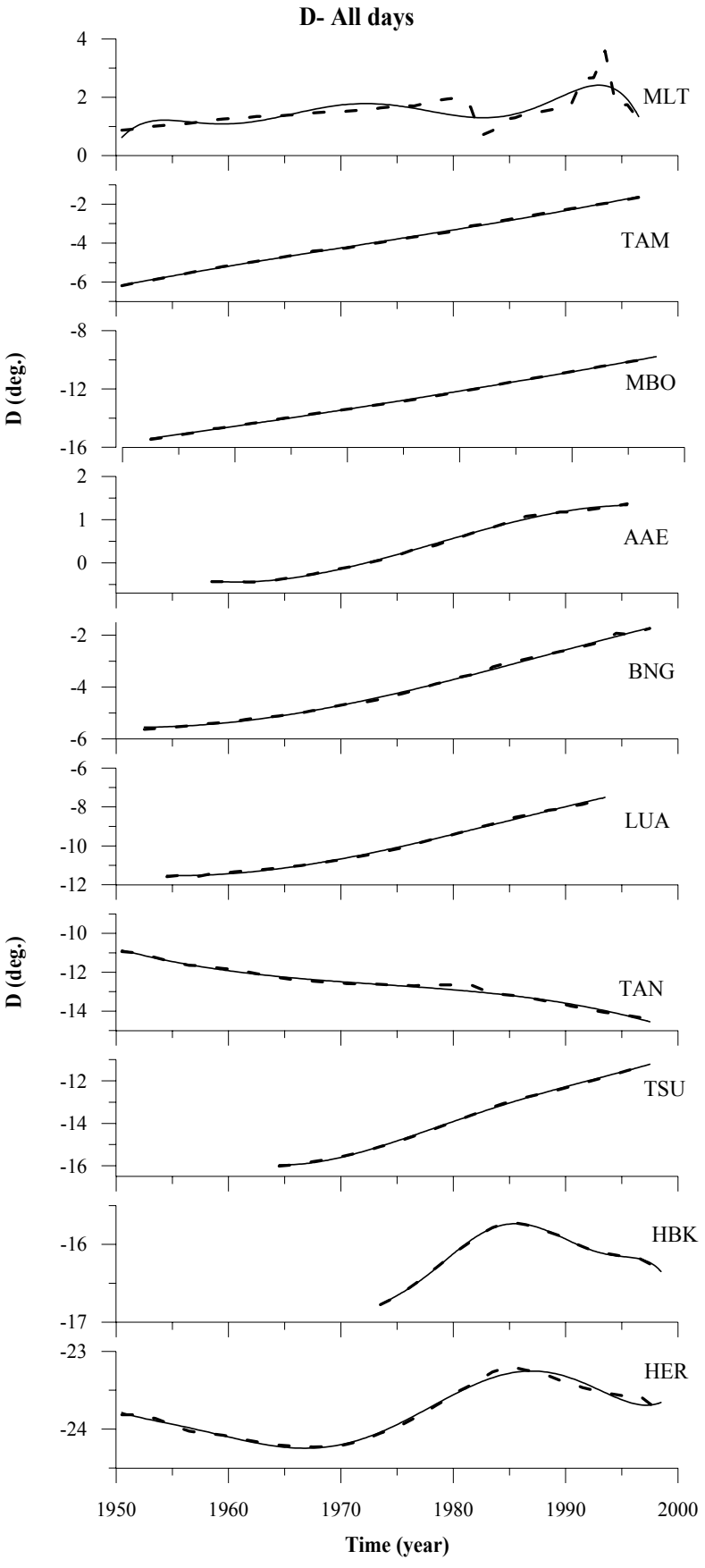

(a)

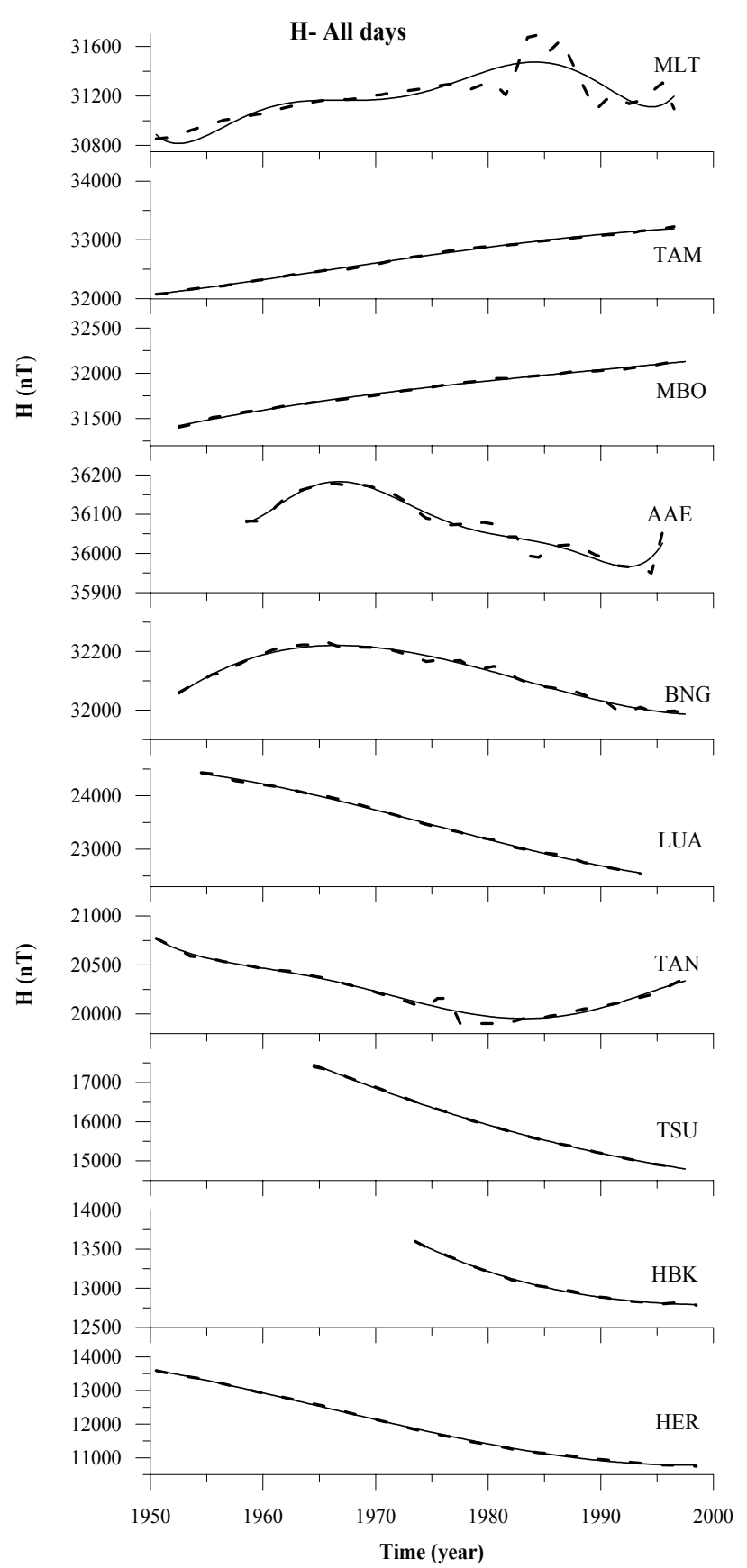

(b)

Fig. 3a and $b$. Observed all day annual mean values of $D$ and $H$ for the ten African observatories for the period 1950-2000 along with their best fitting curves (solid lines). 
A cubic seems to adequately take into account almost all of the secular variations except at the southernmost observatories of Antananarivo, Hartebeesthoek and Hermanus which require polynomials of 5 or higher degree to represent these variations (Table 4). The strong local magnetic anomaly seems to be concentrated on the south and southeastern tip of the continent.

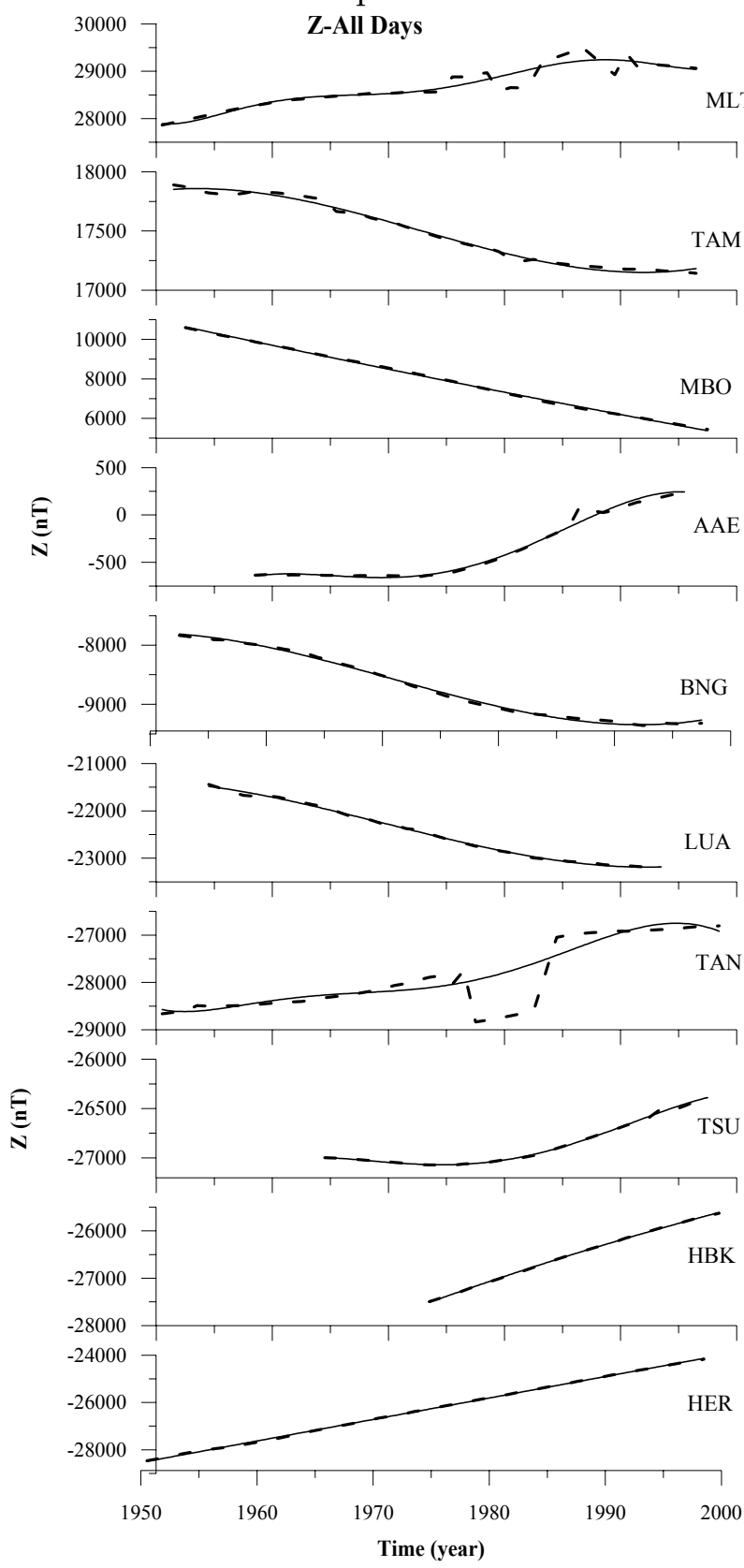

Fig. 3c. Observed all day annual mean values of $\mathrm{Z}$ for the ten African observatories for the period 1950-2000 along with their best fitting curves (solid lines).

The variations in $\mathrm{H}$ plotted in Figure 3(b) show a clear latitudinal dependence. The two equatorial stations of Addis Ababa and Bangui show variations that have similar trends peaking around the middle of the 1960s and decreasing thereafter. These two stations are under the direct influence of the daytime equatorial electrojet that results in enhancements of the daily variation in $\mathrm{H}$. An increase in the value of $\mathrm{H}$ before the 1960s, peaking at about 1965 and decreasing after that is a behaviour similar to that observed over the Indian sector (Bhagrava and Yacob, 1970; Bhardwaj and Rangarajan, 1997) and over the African sector (Tigistu Haile, 2002). Otherwise, all southern latitude stations record decreases in $\mathrm{H}$ while the stations north of the equator show increases in $\mathrm{H}$.

The secular trends at the majority of the observatories are represented by polynomials of the third degree, as can be seen in Table 5, except that a third degree polynomial for the secular trends at Addis Ababa leaves more about $10 \%$ of the data unaccounted for. This is due to the fact that the station being a near dip equatorial station, $\mathrm{H}$ data are strongly modulated by the overhead equatorial electrojet current and other low latitude solar effects.

The $\mathrm{Z}$ variations shown in Figure 3(c) also show latitudinal dependence. The southern observatories show increasing $Z$ while the northern ones show decreasing $Z$ values except the stations at Addis Ababa and Misallat. The picture presented is quite complex here and the southward migration of the dip equator, clearly observed as an increase in $\mathrm{Z}$ at the Indian chain of observatories, is not consistently seen here. The reasons for this could be that the highly localised low-level anomalies, rather than the known sources for secular variation, play important role for the variations in secular trend over Africa. In general, for a good number of stations, it is seen that polynomials of quadratic or at most cubic degree reproduce the secular variations (Table 6).

\section{Residuals}

To obtain the residuals, which possibly contain variations with periods correlable to external signals and solar activity response like the $\sim 11-\mathrm{yr}$ sunspot cycle and the 22-yr double sunspot cycles, the fitted secular trends have been removed from the data. The actual residuals, obtained as the difference between the recorded data from the fitting trends and representing the departures of the data from the long period secular trend, are utilised for this analysis. The fact that all day annual means, rather than the quiet-day mean data, are used in the analysis is appropriate here, as solar cycle effects would still be present in the original data that are expected to reveal themselves in the residuals. 
Table 4. All day annual means of " $\mathrm{D}$ " accounted for by polynomial fits as given by the percentage of variance $\left(\mathbf{R}^{2}\right)$.

\begin{tabular}{|c|c|c|c|c|c|c|}
\hline Station & $1^{\text {st }}$ Deg. & $2^{\text {nd }}$ Deg. & $3^{\text {rd }}$ Deg. & $4^{\text {th }}$ Deg. & $5^{\text {th }}$ Deg. & $6^{\text {th }}$ Deg. \\
\hline MLT & 85.09 & 96.13 & 96.73 & 96.85 & & \\
\hline TAM & 99.83 & 99.90 & 99.93 & & & \\
\hline $\mathrm{MBO}$ & 99.82 & 99.95 & & & & \\
\hline AAE & 97.84 & 98.13 & 99.86 & & & \\
\hline BNG & 97.63 & 99.65 & 99.83 & & & \\
\hline LUA & 97.46 & 98.68 & 99.58 & 99.68 & & \\
\hline TAN & 47.82 & 74.34 & 96.05 & 97.29 & 99.43 & \\
\hline TSU & 99.15 & 99.64 & 99.86 & & & \\
\hline HBK & 15.42 & 92.56 & 94.18 & 98.04 & 99.21 & 99.94 \\
\hline HER & 28.47 & 47.55 & 66.63 & 92.37 & 93.71 & 98.03 \\
\hline
\end{tabular}

Polynomial fits for " $\mathrm{D}$ " for all day annual means

MLT: $-3.7493+0.1373 \mathrm{X}-0.001 \mathrm{X}^{2}-2 \mathrm{E}-05 \mathrm{X}^{3}+2 \mathrm{E}-07 \mathrm{X}^{4}$;

TAM: $-8.2627+0.1275 \mathrm{X}-0.008 \mathrm{X}^{2}+6 \mathrm{E}-06 \mathrm{X}^{3}$

MBO: $-15.492+0.1069 X+0.004 X^{2}$

AAE: $-0.4598+0.0065 X-0.006 X^{2}+0.003 X^{3}-9 \mathrm{E}-06 X^{4}+8 \mathrm{E}-08 X^{5}$

BNG: $-5.0428-0.005 X+0.0033 X^{2}-3 E-05 X^{3}$

LUA: $-11.615+0.0253 X+0.001 X^{2}-0.002 X^{3}-3 E-06 X^{4}$

TAN: $-13.525+0.02143 \mathrm{X}+0.0054 \mathrm{X}^{2}-0.003 \mathrm{X}^{3}+4 \mathrm{E}-06 \mathrm{X}^{4}-2 \mathrm{E}-08 \mathrm{X}^{5}$

TSU: $-16.093+0.041 X+0.0072 X^{2}-0.001 X^{3}$

HBK: $-16.871+0.1092 X+0.0205 X^{2}+0.0056 X^{3}-0.0005 X^{4}+2 E-05 X^{5}-3 E-07 X^{6}$

HER: $-23.753-0.0552 X+0.015 X^{2}-0.0015 X^{3}+6 E-05 X^{4}-1 E-06 X^{5}+6 E-09 X^{6}$

where $X=1,2, \ldots$ represent the years for the corresponding stations for which data is available.

Table 5. All day annual means of " $\mathrm{H}^{\prime}$ accounted for by successive degrees polynomial fits as given by the percentage of variance $\left(R^{2}\right)$.

\begin{tabular}{ccccc}
\hline Station & $1^{\text {st }}$ Deg. & $2^{\text {nd }}$ Deg. & $3^{\text {rd }}$ Deg. & $4^{\text {th }}$ Deg. \\
\hline MLT & 88.61 & 96.78 & 96.78 & 96.84 \\
TAM & 98.2 & 98.47 & 99.04 & \\
MBO & 98.34 & 99.63 & 99.71 & \\
AAE & 71.0 & 75.79 & 91.96 & 92.71 \\
BNG & 58.85 & 90.15 & 98.73 & 93.14 \\
LUA & 99.35 & 99.44 & 99.87 & 99.36 \\
TAN & 91.58 & 97.13 & 99.18 & \\
TSU & 99.31 & 99.89 & & \\
HBK & 92.31 & 99.78 & 99.82 & \\
HER & 98.52 & 99.49 & 99.94 & \\
\hline
\end{tabular}

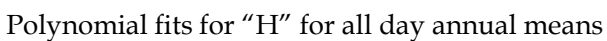

MLT: $30323-34.654 X+1.581 X^{2}-0.015 X^{3}+3 E-05 X^{4}$

TAM: $31923+2.448 X+0.710 X^{2}-0.008 X^{3}$

MBO: $31395+26.267 X-0.3678 X^{2}+0.0031 X^{3}$

AAE: $36077-5.923 X+8.097 X^{2}-1.104 X^{3}-0.058 X^{4}-0.0014 X^{5}+1 E-05 X^{6}$

BNG: $32028+28.65 X-1.249 X^{2}+0.013 X^{3}$

LUA: $24438-23.168 X-1.645 X^{2}+0.028 X^{3}$

TAN: $22880-67.32 X-5.769 X^{2}-0.1198 X^{3}+0.0011 X^{4}-4 \mathrm{E}-06 X^{5}$

TSU: $17558-112.15 \mathrm{X}+0.7916 \mathrm{X}^{2}$

HBK: $13670-74.849 X+1.989 X^{2}+0.016 X^{3}$

HER: $14249+49.522 \mathrm{X}-1.371 \mathrm{X}^{2}-0.021 \mathrm{X}^{3}$

where $X=1,2, \ldots$ represent the years for the corresponding stations for which data is available.

Figure 4 gives the residuals in $\mathrm{D}, \mathrm{H}$ and $\mathrm{Z}$ plotted for the Antananarivo observatory, the station with the longest data series in the region (1890-1999), alongside the solar and double solar cycles. Closer examination of the plots show that the residuals in $\mathrm{D}$ show periodicity of nearly twice the Hale Cycle while those of $\mathrm{H}$ show periodicities nearly matching with the 22-yr Hale Cycle but in phase opposition to it. The residuals in $\mathrm{Z}$ do not exhibit any solar cycle component or its harmonics, and the very large dip in the residual curve observed around 1980 is due to an uncharacteristic decrease in the recorded $\mathrm{Z}$ values around this year (Figure 3c). 
Table 6. All day annual means of " $Z$ " accounted for by successive degrees polynomial fits as given by the percentage of variance $\left(R^{2}\right)$.

\begin{tabular}{ccccc}
\hline Station & $1^{\text {st }}$ Deg. & $2^{\text {nd }}$ Deg. & $3^{\text {rd Deg. }}$ & $4^{\text {th }}$ Deg. \\
\hline MLT & 96.58 & 97.95 & 98.84 & 99.16 \\
TAM & 96.46 & 96.76 & 98.35 & 99.16 \\
MBO & 99.87 & 99.91 & 99.97 & \\
AAE & 83.11 & 96.71 & 97.39 & 98.72 \\
BNG & 95.26 & 97.90 & 99.68 & 99.87 \\
LUA & 96.33 & 99.72 & & 98.08 \\
TAN & 91.97 & 95.66 & 97.84 & 99.42 \\
TSU & 71.63 & 98.94 & 98.98 & 99.78 \\
HBK & 99.82 & 99.98 & 99.99 & \\
HER & 99.97 & 99.98 & 99.99 & \\
\hline
\end{tabular}

Polynomial fits for " $Z$ " for all day annual means

MLT: $25422-21.334 X+3.259 X^{2}-0.047 X^{3}+0.0002 X^{4}$

TAM: $18161-31.785 X+1.715 X^{2}-0.053 X^{3}+0.0005 X^{4}$

MBO: $10651-98.517 X-1.264 X^{2}+0.021 X^{3}$

AAE: $-707.1+53.426 X-9.456 X^{2}+0.5776 X^{3}-0.013 X^{4}+9 E-05 X^{5}$

BNG: $-7901+24.787 X-5.428 X^{2}+0.141 X^{3}-0.0011 X^{4}$

LUA: $-21438-32.009 X-1.819 X^{2}+0.038 X^{3}$

TAN: $-32568-63.205 X+11.816 X^{2}-0.311 X^{3}+0.003 X^{4}-1 E-05 X^{5}$

TSU: $-27009+7.311 X-3.054 X^{2}+0.2026 X^{3}-0.003 X^{4}$

HBK: $-27579+79.697 X+0.337 X^{2}-0.0197 X^{3}$

HER: $-29301+78.281 X+0.4431 X^{2}-0.0046 X^{3}$

where $X=1,2, \ldots$ represent the years for the corresponding stations for which data is available.

Figures $5(a, b, c)$ respectively give the $D, H$ and $Z$ residuals at the ten African observatories for the period 1950-2000. Nearly smooth variations in the residuals with two broad peaks are seen in the record of most of the stations. In the H-residuals, Figure 5(b), a slightly out of phase negative (phase opposition) correlation between the records and the 22-year double solar cycle phenomena is observed for the stations at Hermanus, Tsumeb and Antananarivo while a rather remarkable correlation is shown for M'Bour. The Antananarivo and Luanda Belas stations also show some correlation with this cycle but with some delay in the peaks. The residuals from the Misallat observatory are corrupted by an uncertain data quality from this site after the 1980s. The $\mathrm{Z}$ residuals, Figure 5(c), do not show correlation with solar cycle phenomena except some indications at Luanda Belas and Bangui. A point worth noting here is the rather good similarity, in the residuals in $\mathrm{H}, \mathrm{Z}$ and $\mathrm{D}$ at Hermanus (in phase opposition) and M'Bour (in phase) with periodicities corresponding to the double solar cycle suggesting a strong effect of solar cycle phenomena on the records at these localities. The strong variations in the $\mathrm{Z}$ residuals at Hartebeesthoek could be the result of forcing a higher degree polynomial to fit the data or result of continuous contamination of the record by external fields.

\section{Secular jerks}

Examination of geomagnetic data from worldwide observatories has revealed sudden changes in the trend of the secular variation, which have been called geomagnetic jerks or secular variation impulses. One such rapid, worldwide and simultaneous acceleration in the geomagnetic secular change is believed to have occurred around 1969 and has been discussed by a number of authors. Other less documented impulses have been proposed to occur around 1913 and somewhere around 1980. The date of the wellidentified 1969 impulse was found to be ranging from 1967 and 1972 and was localised to be in 1969.5 over Europe with a duration as short as and even less than 1-yr (Malin and Hodder, 1982; Malin et al., 1983; Le Mouel et al., 1982; Courtillot and Le Mouel, 1984; 1988). There is also a good evidence for up to two years delay in the emergence of the jerk in Australia and Japan. 

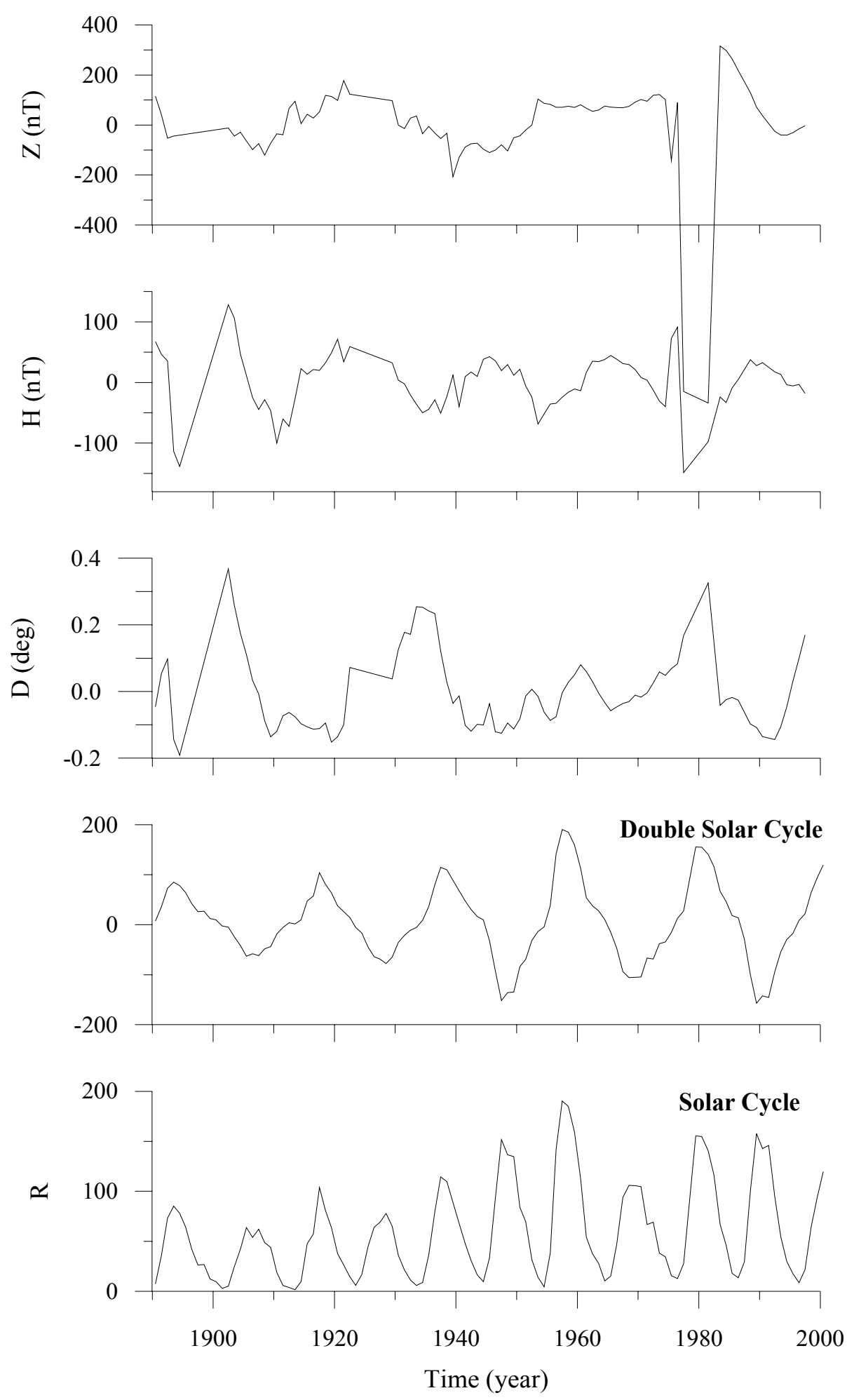

Fig. 4. Residuals in $\mathrm{D}, \mathrm{H}$ and $\mathrm{Z}$ obtained after the secular trends have been removed from all day annual mean data for the period between 1890-2000 at Antananarivo geomagnetic observatory together with the 11-year Wolf's number and Hale Cycles.

Several techniques have been proposed to The more classical method of analysing the trend identify the occurrence of geomagnetic impulses in secular variation involves displaying the first from geomagnetic data (Courtillot and Le Mouel, derivatives that are computed from first order 1988; Alexandrescu et al., 1996; Mandea et al., 2000). finite differences of annual mean values of the 
geomagnetic components against time. A change in slope of the curves, fitted in the least squares sense, indicates the presence of such phenomena providing a very clear and convincing picture of the impulse. As a first approximation, therefore,
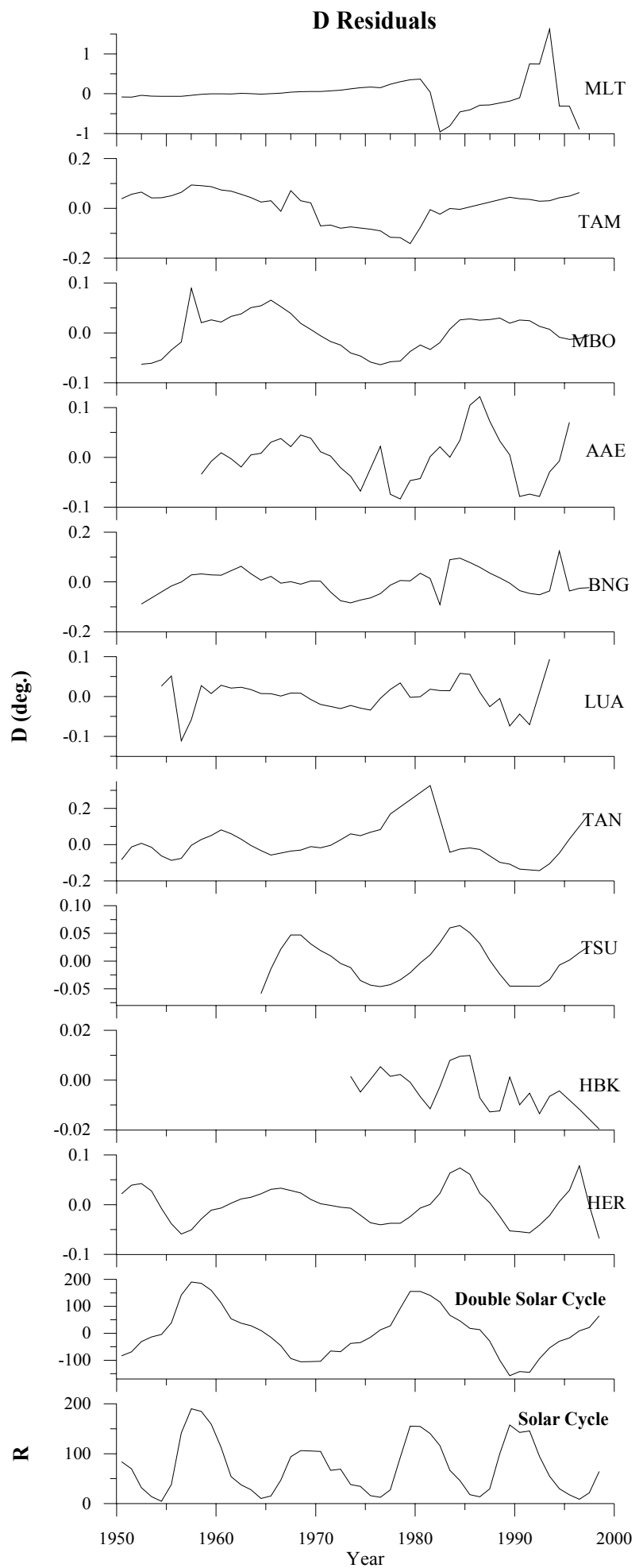

(a) the secular variation impulse can be represented as a two-segment broken line with an apparently worldwide and synchronous break occurring around the year of the impulse (1969). This technique has been employed in this work.

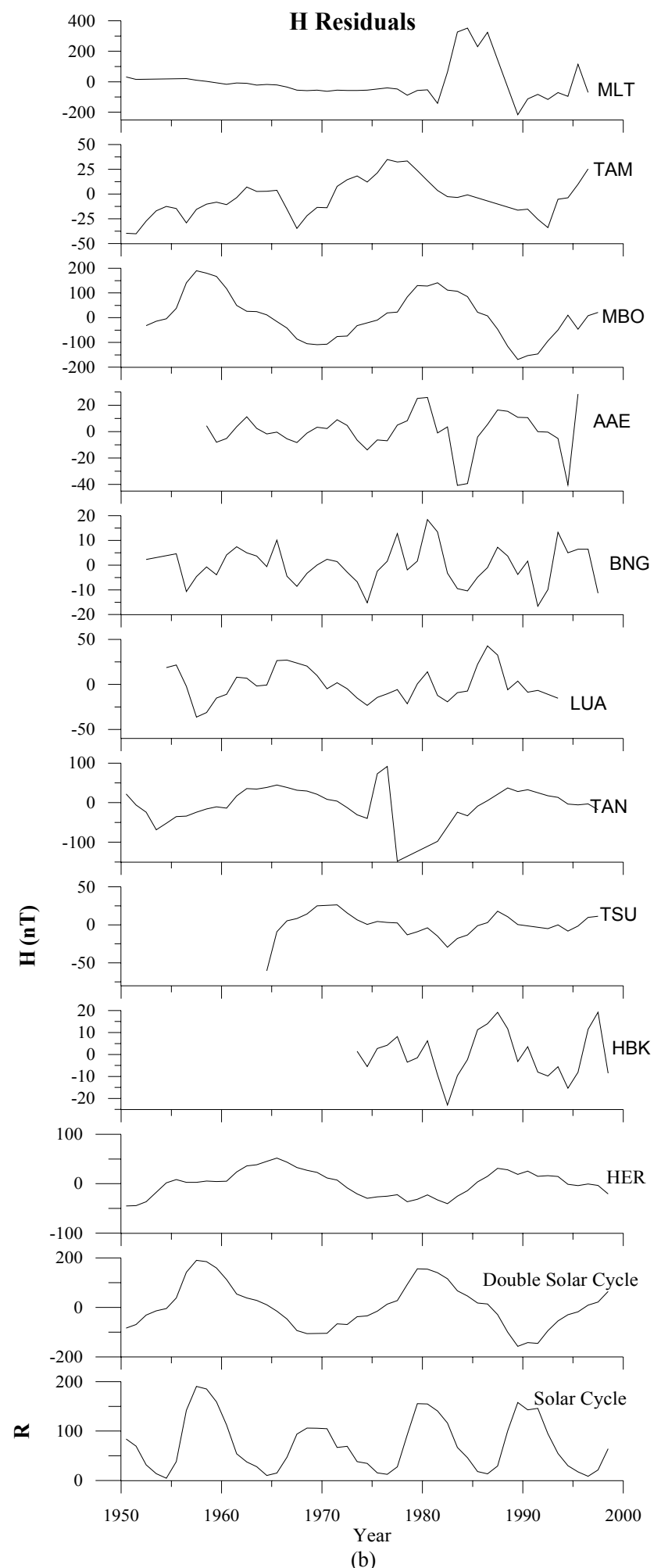

(b)

Fig. $5 \mathrm{a}$ and $\mathrm{b}$. Residuals in $\mathrm{D}$ and $\mathrm{H}$ at the ten African Observatories obtained after the secular trends have been removed from all day annual mean data for the period 1950-2000 together with the 11-year Wolf's number and Hale Cycle. 


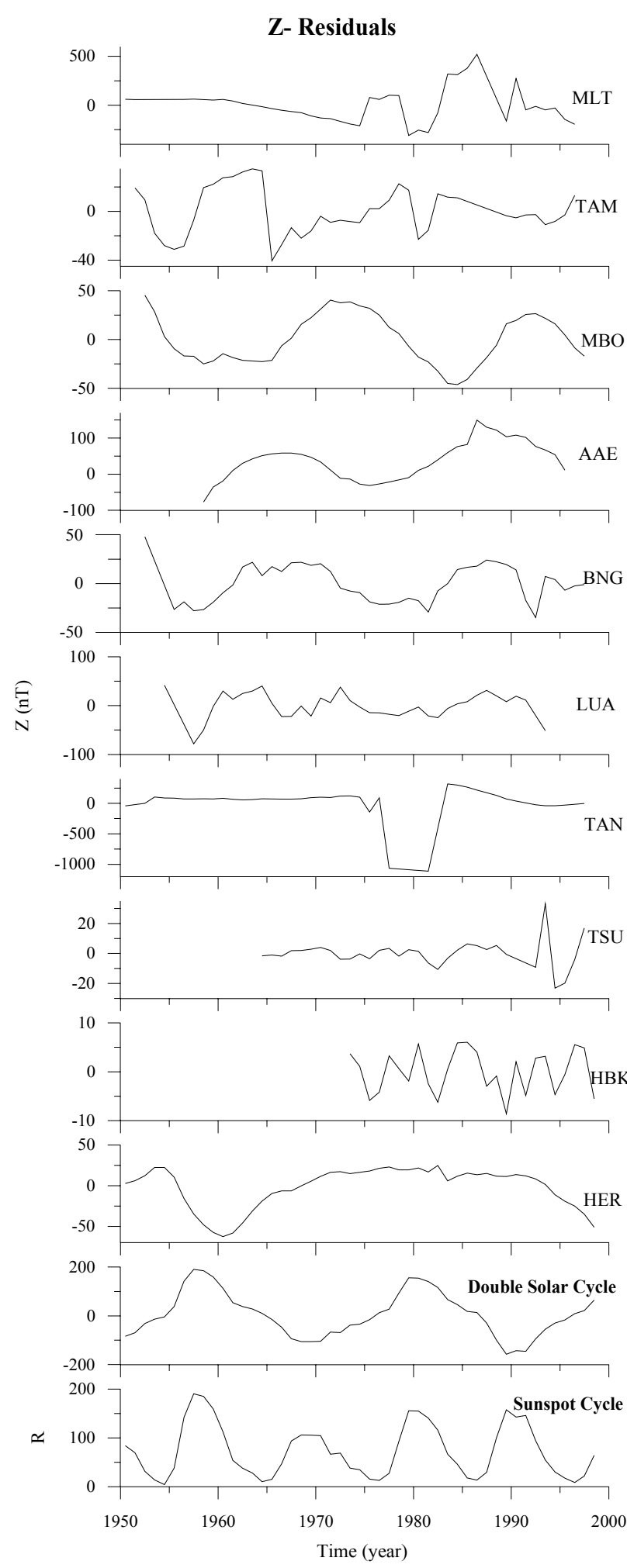

Fig. 5c. Residuals in $\mathrm{Z}$ at the ten African Observatories obtained after the secular trends have been removed from all day annual mean data for the period 19502000 together with the 11-year Wolf's number and Hale Cycle.
The impulse was observed in the east $(\mathrm{Y} \equiv \mathrm{D})$ component at European observatories and was well identified in 38 observatories from the Northern Hemisphere (Le Mouel et al., 1982). It was identified in the $\mathrm{H}$ component in the North American region and in the $\mathrm{Z}$ component in the far eastern hemispheres/Australasian and Siberian region (Whaler, 1987). Bhardwaj and Ragaranjan (1997) on the other hand have detected the change in slope on both the $\mathrm{H}$ and $\mathrm{Z}$ components for the Indian chain of observatories. Most of these studies have also shown a strong suggestion for an impulse around 1980.

Systematic examination of the presence of the secular variation impulse in these records has not been carried out except the use of the Hermanus data in some works. In this section, attempt is made to look for this signature of the secular variation impulse and examine which components show this change in the African region.

\section{The 1969.5 secular jerk over Africa}

Figures $6(\mathrm{a}, \mathrm{b}, \mathrm{c})$ give the plots of the first differences in $\mathrm{D}, \mathrm{H}$ and $\mathrm{Z}$ for the ten African observatories. From the plots in Figure 6(a), which give the first derivatives of $\mathrm{D}$ with time, no clear signature of the 1969 event is evident in D except some indications for the northern stations of M'Bour and Tamanrasset. The plots, however, are suggestive of a change in slope around 1980 for most of the southern and equatorial observatories, more specifically for the observatories at вк Hermanus, Hartebeesthoek, Tsumeb, Luanda Belas, Bangui and Addis Ababa. From the plots of the first differences in $\mathrm{H}$ (Figure 6(b)), the 1969 event is observable in the southernmost observatories of Hermanus, Hartebeesthoek and Tsumeb through the existence of a bi-linear curve in the $\mathrm{dH} / \mathrm{dt}$ plot around this year. The low latitude and equatorial stations of Antananarivo, Luanda Belas, Bangui and Addis Ababa show the signature for the 1969 event in their Z-first difference plots (Figure 6(c)). It is not possible to find any indication of the impulse for station at Misallat in the far north and this appears to be mainly due to data quality, which has made the analysis unreliable. It can be said, therefore, that in the African observatory geomagnetic records the 1969 worldwide event appears to be evident in one or the other of the geomagnetic elements with a certain systematic latitudinal distribution. 
First Differences in D

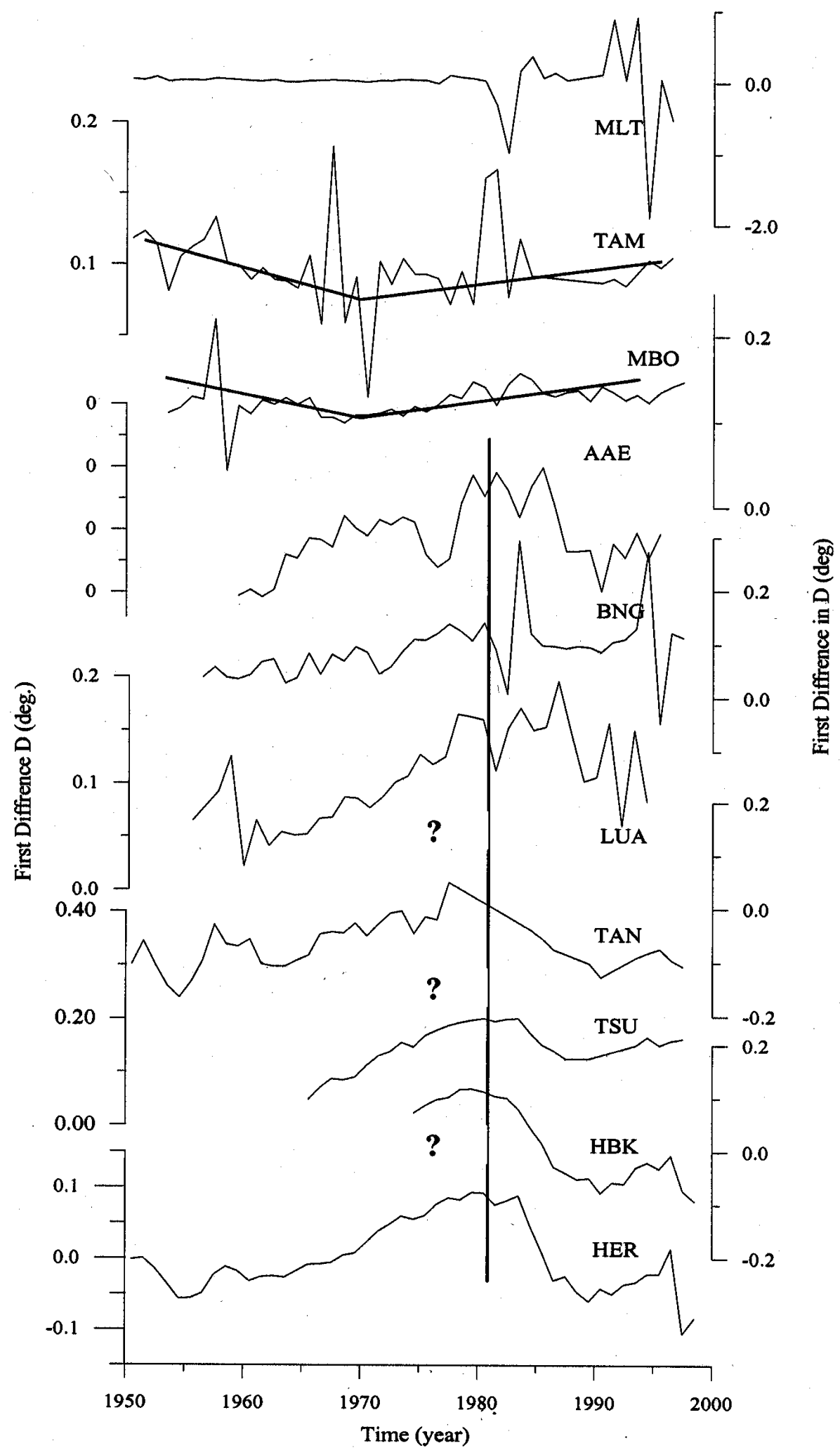

Fig. 6a. First difference of annual mean values of $D$ for the ten African Observatories for the period between 1950-2000, with bi-linear trends fitted to the data. 


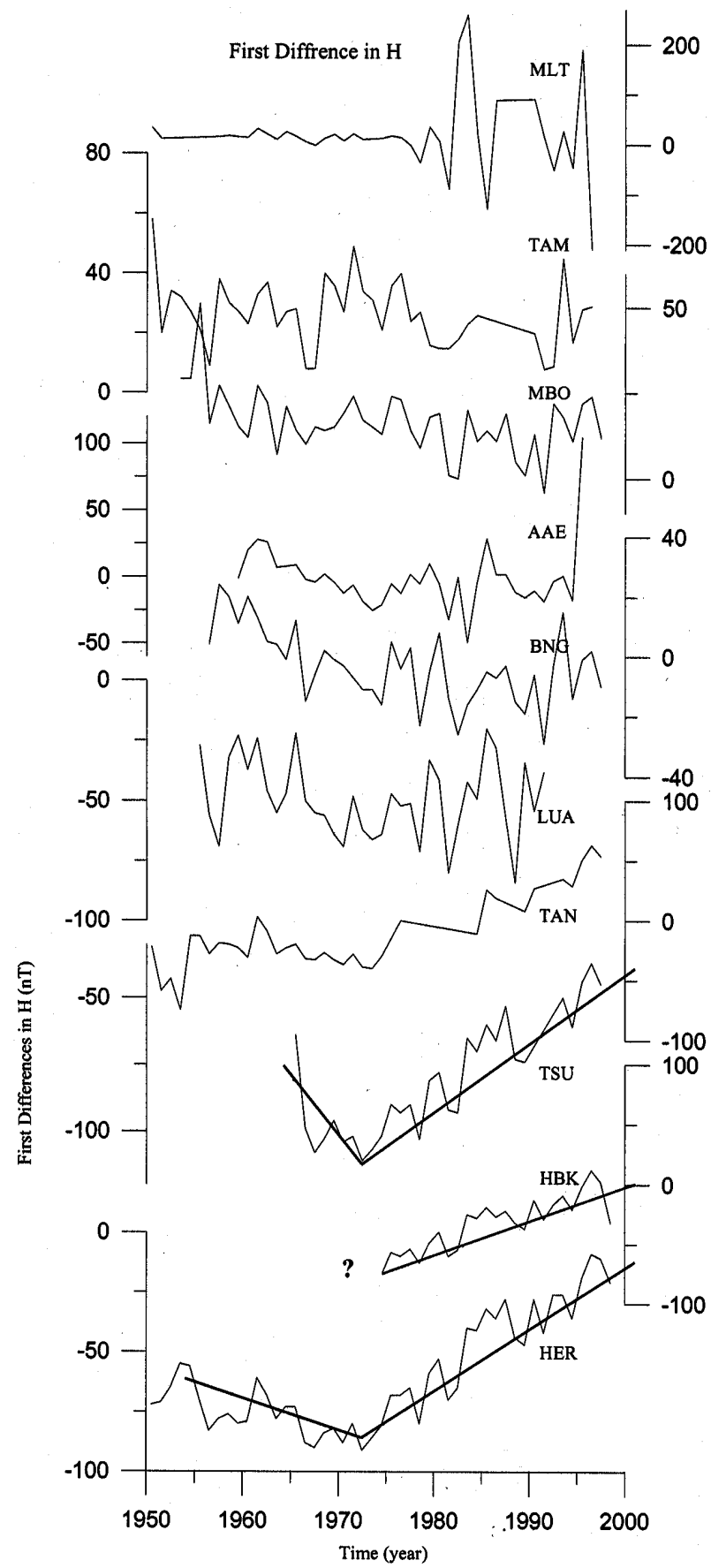

(b)

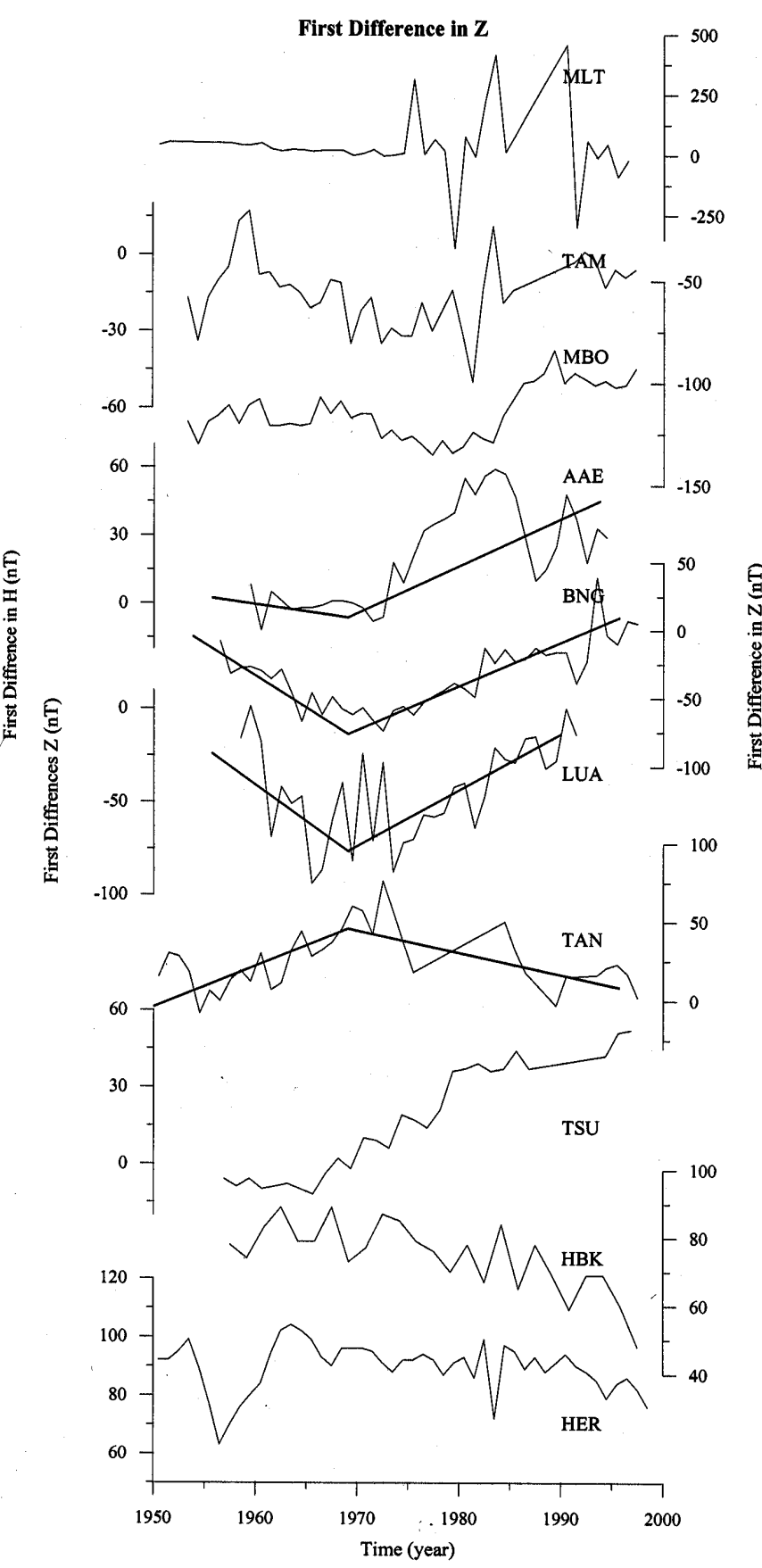

(c)

Fig. $6 \mathrm{~b}$ and c. First difference of annual mean values of $\mathrm{H}$ and $\mathrm{Z}$ for the ten African Observatories for the period 1950-2000, with bi-linear trends fitted to the data.

\section{SUMMARY}

From the results of the analysis carried out on observatory recorded data in the African region, it is observed that a low-degree quadratic, and a cubic in most instances, is adequate to represent the long period secular variations of the geomagnetic field over the continent. This verifies that the African continent, for the most part, is without strong local anomalies and the sources for the secular variation are deep seated. Departures from this trend are observed over the Southern African region where a strong local geomagnetic anomaly has been known to exist. In this region a polynomial of degree six or even higher would be required to represent this variation.

The residuals in the geomagnetic field components obtained after the removal of the best 
fitting polynomial trends do not show, with consistency, evidence of parallelism with solar cycle or double solar cycle phenomena. For some stations, like that of Hermanus and $\mathrm{M}^{\prime}$ Bour there is some correspondence with periodicities of double sunspot cycle although the variations are in phase opposition for Hermanus.

It was possible to study the signature of the 1969-70 geomagnetic jerk over trans-equatorial observatories as the stations used in the study include both equatorial and low latitude stations $\left(29.5^{\circ} \mathrm{N}\right.$ to $\left.34.4^{\circ} \mathrm{S}\right)$. For the southern most stations of Hermanus, Hartebeesthoek and Tsumeb, the signatures of the 1969-70 geomagnetic jerk appear in the first difference plots of $\mathrm{H}$ (Figure 6(b)). The equatorial and low latitude stations of Antananarivo, Luanda Belas, Bangui and Addis Ababa show the existence of the jerk in the plots of the first difference in $\mathrm{Z}$ while the northern stations of $\mathrm{M}^{\prime}$ Bour and Tamanrasset show indication of the jerk in the first difference plots in D. More evident in the plots of first differences in D (Figure 6(a)) is, however, the rather strong suggestion for the presence of an impulse in secular variation around 1980 at most of the stations.

In addition to studying the different aspects of the geomagnetic field, the work also in general puts the available geomagnetic observatory data from the African continent in perspective. Through this, it is seen that the data quality at some of the stations has large jumps, as for example at Misallat after around 1980, rendering the data unreliable to permit examination of the finer behaviour in the variations of the geomagnetic field. It is hoped that with the introduction of the INTERMAGNET, which most of the stations studied here have joined, and standard instrumentation and calibration techniques these problems would be removed and reliable data can be acquired.

\section{ACKNOWLEDGEMENTS}

This work was carried out while the author was on his third visit to the Abdus Salam International Centre for Theoretical Physics (ICTP), Trieste, Italy as a Regular Associate and as an ICTPTraining and Research in Italian Laboratories (TRIL) Fellow. The author acknowledges the sponsorship of the Swedish International Development Agency (SIDA) who financed the Associateship, the TRIL programme, and also ICTP for the excellent library facilities and, above all, the exceptional working environment. The author also acknowledges Prof. Roberto Balia of the
University of Cagliari and Prof. S. Radicella, Head of the Aeronomy and Radio-propagation Laboratory of the ICTP under whose guidance and supervision this work was carried out. This paper has appeared as an ICTP preprint (IC/2002/140; January, 2003) and was orally presented at the XI'th IAGA Workshop on Geomagnetic Instruments, Data Acquisition and Processing held in Tsukuba, Japan during 9-17 November 2004 .

\section{REFERENCES}

1. Achache, J., Courtillot, V., Ducruix, J. and Le Mouel, J.-L. (1980). The late 1960's secular variation impulse: Further constraints on deep mantle conductivity. Phys. Earth Planet Inter. 23:72-75.

2. Alexandrescu, M., Gilbert, D., Hulot, G., Le Mouel, J.L. and Saracco, G. (1996). Worldwide wavelet analysis of geomagnetic jerks. J. Geophys. Res. 101(B10):21975-21994.

3. Alexandrescu, M., Courtillot, V. and Le Mouel, J.-L. (1997). High-resolution secular variation of the geomagnetic field in Western Europe over the last four centuries: Comparison and integration of historical data from Paris and London. J. Geophys. Res. 102(B9):20245-20258.

4. Alldredge, L.R. (1983). Varying geomagnetic anomalies and secular variation. J. Geophys. Res. 88:9443-9451.

5. Baldwin, R.J. and Langel, R. (1993). Tables and maps of the DGRF-1985 and IGRF-1990. IAGA Bull. No. 54. ISGI Publ. Office, France.

6. Banks, R.J. (1969). Geomagnetic variations and the electrical conductivity of the upper mantle. Geophys. J. R. Astron. Soc. 17:457-487.

7. Bhagrava, B.N. and Yacob, A. (1970). The secular variation of the magnetic field and its cyclic components. J. Atmos. Terr. Phys. 32:365-372.

8. Bhardwaj, S.K. and Rangarajan, G.K. (1997). Geomagnetic secular variation at the Indian Observatories. J. Geomag. Geoelectr. 49:1131-1144.

9. Bloxham, J. and Gubbins, D. (1985). The secular variation of the Earth's magnetic field. Nature 317:777-781.

10. Campbell, W.H. (1980). Secular, annual, and semiannual changes in the baseline level of the Earth's magnetic field at North American locations. J. Geophys. Res. 85:6557-6571.

11. Courtillot, V. and Le Mouel, J.-L. (1976). On the long period variations of the Earth's magnetic field from 2 months to 20 years. J. Geophys. Res. 81:2941-2950. 
12. Courtillot, V. and Le Mouel, J.-L. (1984). Geomagnetic secular variation impulses. Nature 311:709-716.

13. Courtillot, V. and Le Mouel, J.-L. (1988). Time variations of the Earth's magnetic field: from daily to secular. Annu. Rev. Earth Planet Sci. 16:389-476.

14. Ducruix, J., Courtillot, V. and Le Mouel, J.-L. (1980). The late 1960 secular variation impulse, the eleven-year magnetic variation and the electrical conductivity of the deep mantle. Geophys. J. R. Astr. Soc. 61:73-94.

15. Gangi, A.F. and Shapiro, J.N. (1977). A propagating algorithm for determining the $\mathrm{n}^{\text {th }}$ order polynomial least square fits. Geophys. 42:1265-1276.

16. Gavoret, J., Gilbert, D., Melville, M. and Le Mouel, J.L. (1986). Long term variations of the external and internal components of the Earth's magnetic field. J. Geophys. Res. 91:4787-4796.

17. Gubbins, D. and Tomlinson, L. (1986). Secular variation from monthly means from Apia and Amberley magnetic observatories. Geophys. J. R. Astr. Soc. 86:603-616.

18. Le Mouel, J.-L., Ducruix, J. and Duyen, C.H. (1982). The worldwide character of the 1969-70 impulse of the secular acceleration rate. Phys. Earth Planet Int. 28:337-350.
19. Malin, S.R.C. and Hodder, B.M. (1982). Was the 1970 geomagnetic jerk of internal or external origin? Nature 296:726-728.

20. Malin, S.R.C., Hodder, B.M. and Barraclough, D.R. (1983). Geomagnetic secular variation: A jerk in 1970. Ebro. Observ. Mem. Publ. 14:239-256.

21. Mandea, M., Bellanger, E. and Le Mouel, J.-L. (2000). A geomagnetic jerk for the end of the $20^{\text {th }}$ century? Earth Plant Sci. Lett. 183:369-373.

22. Rangarajan, G.K., Velizand, O. and Arora, B.R. (1996). Geomagnetic secular variation and field oscillations of external origin at Huancayo, Peru. Brazilian J. Geophys. 14(1):29-40.

23. Rao, D.R.K. and Bansal, R.K. (1969). Secular variation of geomagnetic elements at Alibagh. Indian J. Meteorol. Geophys. 20:137-144.

24. Tigistu Haile (2002). Geomagnetic secular variation at Addis Ababa over the last four decades: comparison with 1945-2000 IGRF models. SINET: Ethiop. J. Sci. 25(1):83-95.

25. Whaler, K.A. (1987). A new method of analysing geomagnetic impulses. Phys. Earth Planet Int. 48:221-240. 